INOBIS: Jurnal Inovasi Bisnis dan Manajemen Indonesia

Volume 1, Nomor 2, Maret 2018

Ratna Mentari; Andian Ari Istiningrum

\title{
Evaluasi Kebutuhan Unit Filling Machine LPG Kemasan Tabung 3 KG: Studi Kasus pada Depot LPG X
}

\author{
Ratna Mentari, Andian Ari Istiningrum \\ Politeknik Energi dan Mineral (PEM Akamigas) \\ mentari.na21@gmail.com; aa_istiningrum@esdm.go.id
}

\begin{abstract}
$L P G X$ Depot has three main functions to receive, store, and distribute LPG $3 \mathrm{~kg}$ to SPPBE, SPBE, and agencies. The distribution of LPG $3 \mathrm{~kg}$ has increased $39.29 \%$ during 2012-2016. Therefore, the LPG filling process using unit filling machine (UFM) has experienced high load from year to year. This research has objectives to evaluate the effectiveness of standard operating procedure (SOP) of LPG filling process, to predict LPG 3 $\mathrm{kg}$ sales during 2017-2021, and to evaluate the number of UFM needed by LPG X Depot to fulfill the sales during 2017-2021. The research are descriptive qualitative research. The data regarding the effectiveness of LPG filling process SOP and the capacity of UFM were collected throgh observations; whereas the data regarding the sales of LPG during 20122016 was collected through documentation. The data was analyzed descriptively. The results show that: (1) the SOP of LPG filling process is effective with the effectiveness rate about $94.44 \%$, (2) there will be a growth for $8.71 \%$ per year in the number of LPG $3 \mathrm{~kg}$ sales, and (3) there will be a need to add the number of UFM from 7 unit in 2017 to 16 units in 2021 to fulfill the increase of sales.
\end{abstract}

Kata kunci: LPG, unit filling machine, prediksi penjualan

\section{Pendahuluan}

Liquid Petroleum Gas (LPG) merupakan salah satu sumber energi yang saat ini diminati oleh masyarakat baik masyarakat golongan rumah tangga maupun industri. Konsumsi LPG $3 \mathrm{~kg}$ pada tahun 2016 meningkat 6.602 juta ton atau 14,5\% dari tahun sebelumnya (Gumelar, 2015). Konsumsi LPG terutama dimulai sejak tahun 2007 ketika pemerintah melaksanakan program konversi minyak tanah ke LPG. Konversi energi dilakukan karena biaya pengolahan minyak tanah setara dengan biaya pengolahan avtur, selain itu subsidi minyak tanah tidak tepat sasaran (Rizky, 2007). LPG dipilih sebagai pengganti minyak tanah karena biaya produksi LPG sebesar Rp 4.200,00 per liter lebih rendah dari biaya produksi minyak tanah sebesar Rp 6.700,00 per liter. LPG memiliki nilai kalori yang lebih tinggi dan lebih bersih sehingga tidak menimbulkan emisi hasil pembakaran. Selain itu, LPG lebih mudah didistribusikan ke daerah yang jauh dari supply point dan lebih ramah lingkungan (PT Pertamina, 2007).

Pengelolaan LPG mulai dari pengadaan LPG hingga pemasaran kepada konsumen dilakukan oleh PT Pertamina Direktorat Pemasaran dan Niaga. Pengelolaan LPG terdiri atas pengelolaan Public Service Obligation (PSO) yaitu LPG tabung $3 \mathrm{~kg}$ yang mendapat subsidi dari pemerintah dan Non PSO yang tidak mendapat subsidi dari pemerintah. Depot LPG X merupakan salah satu depot penerimaan, penimbunan, dan penyaluran LPG yang berada di bawah fungsi Domestic Gas Region IV PT Pertamina. LPG disuplai dari Recidual Fuel Catalytic Cracking (RFCC) dan Fuel Oil Complex (FOC) Refinery Unit IV X. LPG Depot X 
INOBIS: Jurnal Inovasi Bisnis dan Manajemen Indonesia

Volume 1, Nomor 2, Maret 2018

Ratna Mentari; Andian Ari Istiningrum

disalurkan ke Stasiun Pengangkutan dan Pengisian Bulk Elpiji (SPPBE) dan industri. Produk yang disalurkan yaitu Elpiji $3 \mathrm{~kg}, 5,5 \mathrm{~kg}, 12 \mathrm{~kg}$,dan $50 \mathrm{~kg}$.

Salah satu tanggung jawab utama Depot LPG $X$ yaitu menjamin kelancaran penyaluran LPG ke SPPBE dan SPBE serta menjamin tercukupinya penyaluran LPG ke agen sesuai dengan prosedur yang berlaku. Proses pengisian LPG kemasan tabung menggunakan alat yang disebut Unit Filling Machine (UFM). UFM adalah mesin pengisian yang didesain untuk proses pengisian yang aman dan akurat. UFM menggunakan sistem prinsip berat dan aliran massa dimana proses pengisian bisa dilakukan dengan otomatis maupun semi otomatis. UFM dapat diatur untuk mengisi tabung dengan berat yang ditentukan dengan keakuratan yang tinggi. Kelebihan pengisian LPG dengan menggunakan UFM yaitu: (1) biaya instalasi rendah, (2) pemeliharaan mudah, (3) membutuhkan tenaga yang kecil, dan (4) memiliki sistem keamanan yang terinstal pada PC (The Kosan Crisplant Group, 2014).

UFM merupakan rangkaian yang tersusun atas beberapa peralatan yang mendukung proses pengisian produk LPG, meliputi: (1) Palletizing Systems, berfungsi untuk membuat penanganan pada proses bongkar maupun muat, (2) Conveyor System, berfungsi untuk memudahkan pemindahan tabung LPG secara otomatis dari proses bongkar, pengisian, hingga proses muat, (3) Carrousel Filling System, berfungsi untuk menjadikan proses pengisian lebih aman dan efektif (The Kosan Crisplant Group, 2014). UFM memiliki beberapa komponen peralatan yang terdiri atas: (1) Filling Head, berfungsi sebagai katup untuk menghubungkan pipa UFM ke tabung LPG pada pengisian produk, (2) Checking Weighing System, berfungsi untuk mengkoreksi berat bersih pada masing-masing tabung LPG, (3) Leak Testing Bath, berfungsi untuk mengetes adanya kebocoran pada tabung LPG, dan (4) Evacuation System, berfungsi untuk melakukan evakuasi pada tabung LPG yang mengalami kebocoran (The Kosan Crisplant Group, 2014).

Observasi pendahuluan pada proses pengisian LPG kemasan tabung $3 \mathrm{~kg}$ dengan UFM di Depot LPG X menunjukkan bahwa masih terdapat beberapa masalah yang muncul pada operasi pengisian LPG yang menimbulkan ancaman bagi tercukupinya kebutuhan LPG di wilayah Jawa Tengah bagian selatan dan DIY. Pada saat UFM dioperasikan, pemberian oil secukupnya pada filling head dan pembuangan sisa angin pada kompresor tidak dilakukan sehingga hal ini dapat mempercepat kerusakan UFM. Standard Operational Procedure (SOP) pengoperasian UFM oleh karena itu belum sepenuhnya dilaksanakan dalam proses pengisian LPG tabung kemasan $3 \mathrm{~kg}$.

Operasi pengisian LPG kemasan tabung $3 \mathrm{~kg}$ masih dilakukan secara semi otomatis di kawasan Filling Plant sehingga beberapa sarana fasilitas (sarfas) pengisian LPG masih memerlukan operator untuk kegiatan pengisian LPG. Proses bongkar dan muat dilakukan secara manual dan belum menggunakan sistem chain conveyor dan carousell. Proses bongkar muat manual membutuhkan waktu yang cukup lama yaitu 15 menit dibandingkan proses otomatis yang hanya membutuhkan waktu 5 menit.

Proses pengisian LPG kemasan tabung $3 \mathrm{~kg}$ dengan UFM di Depot LPG X mengalami load yang tinggi dari tahun ke tahun. Penumpukan antrian pengisian tabung $3 \mathrm{~kg}$ di filling shed masih sering terjadi. Filling shed tabung $3 \mathrm{~kg}$ hanya mampu melayani satu truk untuk satu kali kegiatan bongkar muat dari yang seharusnya mampu melayani dua truk dalam sekali proses bongkar muat. Load yang tinggi pada pengisian filling shed $3 \mathrm{~kg}$ menyebabkan Depot LPG $\mathrm{X}$ harus melakukan penambahan jam operasional diluar jam kerja normal. Tambahan jam kerja selama 2 jam setiap hari kerja dan jam kerja pada hari Sabtu dan Minggu menyebabkan biaya operasional membengkak.

Peningkatan permintaan LPG kemasan tabung $3 \mathrm{~kg}$ di wilayah Jawa Tengah bagian selatan dan DIY menimbulkan konsekuensi bagi Depot LPG X untuk dapat memenuhi permintaan LPG. LPG kemasan tabung $3 \mathrm{~kg}$ sangat diminati masyarakat terutama masyarakat 
INOBIS: Jurnal Inovasi Bisnis dan Manajemen Indonesia

Volume 1, Nomor 2, Maret 2018

\section{Ratna Mentari; Andian Ari Istiningrum}

rumah tangga dimana penjualan LPG kemasan tabung $3 \mathrm{~kg}$ dari tahun 2012 sampai tahun 2016 mengalami kenaikan sebesar 39,29\%. Oleh karena itu, perkiraan peningkatan penjualan LPG kemasan tabung $3 \mathrm{~kg}$ perlu dilakukan sebagai dasar untuk mengevaluasi kebutuhan sarfas pengisian LPG (UFM) sehingga tidak akan terjadi kekosongan pasokan LPG kemasan tabung $3 \mathrm{~kg}$. Berdasarkan permasalahan tersebut, maka penelitian ini bertujuan untuk: (1) mengevaluasi efektivitas prosedur pengisian LPG kemasan tabung $3 \mathrm{~kg}$ di Depot LPG X, (2) memprediksi penjualan/penyaluran LPG kemasan tabung $3 \mathrm{~kg}$ di Depot LPG X untuk jangka waktu 5 tahun mendatang, yaitu periode 2017-2021, dan (3) mengevaluasi kebutuhan UFM pengisian LPG kemasan tabung $3 \mathrm{~kg}$ periode 2017-2021 sehingga mampu dijadikan dasar perencanaan penyediaan UFM yang handal guna memenuhi tercukupinya distribusi LPG.

\section{Metode Penelitian}

\section{Jenis Penelitian}

Penelitian ini merupakan penelitian deskriptif kualitatif yang tidak menguji hubungan antar variabel. Penelitian dilakukan untuk menangkap fenomena dalam penelitian yaitu analisis efektivitas prosedur pengisian LPG kemasan tabung $3 \mathrm{~kg}$ dan evaluasi kebutuhan UFM untuk pengisian tabung $3 \mathrm{~kg}$ untuk periode 5 tahun ke depan berdasarkan tingkat penjualan/penyaluran LPG kemasan tabung $3 \mathrm{~kg}$ yang kemudian mendeskripsikan hasilnya dalam bentuk angka.

\section{Teknik Pengumpulan Data}

Data mengenai efektivitas prosedur pengisian LPG kemasan tabung $3 \mathrm{~kg}$ berupa data primer yang dikumpulkan melalui observasi pelaksanaan Standard Operating Procedure (SOP) pengisian LPG kemasan tabung $3 \mathrm{~kg}$ yang berlaku di Depot LPG X yang terdiri atas:

(1) kelengkapan dokumen dan sarana fasilitas pengisian, (2) prosedur administrasi pengisian, (3) prosedur persiapan pengisian, (3) prosedur proses pengisian dan pengoperasian UFM, dan (4) prosedur penyelesaian pengisian. Observasi dilakukan dengan menggunakan check list yang terdiri atas 2 kriteria yaitu: (1) ya; jika prosedur di SOP dilaksanakan di lapangan, dan (2) tidak; jika prosedur di SOP tidak dilaksanakan di lapangan. Tabel 1, 2, 3, 4, dan 5 menunjukkan check list yang digunakan dalam observasi.

Tabel 1. Check List SOP Kelengkapan Dokumen dan Sarfas Pengisian

\begin{tabular}{cll}
\hline No & \multicolumn{1}{c}{ Kriteria } & Ya \\
\hline 1 & Kelengkapan Dokumen: & \\
& a. Surat Jalan & \\
& b. Loading Order (LO) & \\
& c. Tanda Penukaran & \\
& d. Buku Laporan Harian & \\
& Kelengkapan Sarfas Pengisian \\
& a. Tabung Elpiji 3 kg \\
& b. Rubber Seal \\
& c. Security Seal Cap \\
& d. Wrapping Plastic \\
& e. UFM 3 kg \\
& f. Air Compressor \\
& g. Transfer Pump
\end{tabular}


INOBIS: Jurnal Inovasi Bisnis dan Manajemen Indonesia

Volume 1, Nomor 2, Maret 2018

Ratna Mentari; Andian Ari Istiningrum

h. Timbangan Cross Check

i. Evacuation Pump

Sumber : Hasan, 2014

Tabel 2. Check List SOP Administrasi Pengisian

\begin{tabular}{clll}
\hline No & \multicolumn{1}{c}{ Kriteria } & Ya & Tidak \\
\hline 1 & Agen melakukan pembayaran melalui bank sehari & \\
& $\begin{array}{l}\text { sebelum pengisian LPG. } \\
\text { Agen menyetorkan bukti pembayaran ke pihak }\end{array}$ & \\
& $\begin{array}{l}\text { administrasi depot saat akan melakukan pengisian. } \\
\text { Agen mengambil loading order di bagian } \\
\text { administrasi penjualan depot LPG. }\end{array}$ \\
4 & $\begin{array}{l}\text { Pemeriksaan loading order oleh gate keeper } \\
\text { Setelah pengisian, loading order ditukar dengan } \\
\text { surat jalan yang berisi tujuan pengiriman }\end{array}$ \\
\hline
\end{tabular}

Sumber : Hasan, 2014

Tabel 3. Check List SOP Persiapan Pengisian

\begin{tabular}{clll}
\hline No & \multicolumn{1}{c}{ Kriteria } & Ya & Tidak \\
\hline 1 & $\begin{array}{l}\text { Pemeriksaan surat jalan yang telah diregistrasi oleh } \\
\text { gate keeper. }\end{array}$ & \\
2 & $\begin{array}{l}\text { Penghitungan jumlah tabung kosong disesuaikan } \\
\text { dengan surat jalan. }\end{array}$ & \\
3 & $\begin{array}{l}\text { Pembongkaran tabung kosong dari dalam truk. } \\
4\end{array}$ & \\
5 & Susun tabung kosong di dekat UFM. \\
& Pemeriksaan visual apakah tabung layak untuk \\
6 & $\begin{array}{l}\text { Tabung tidak layak pakai ditukar dengan tabung } \\
\text { yang layak pakai. }\end{array}$ \\
\hline
\end{tabular}

Sumber : Hasan, 2014

Tabel 4. Check List SOP Pengoperasian UFM

\begin{tabular}{cll}
\hline No & \multicolumn{1}{c}{ Kriteria } & Ya \\
\hline 1 & Persiapan & \\
& a. Gunakan Alat Pelindung Diri (APD). \\
& b. Tempatkan operator pengisian di UFM masing- \\
& masing. \\
& c. Beri oil secukupnya pada filling head. \\
& d. Buang sisa angin pada kompresor. \\
& e. Siapkan material yang digunakan (rubber seal, \\
& security seal cap, dan plastic wrap). \\
& f. Tekan tombol listrik warna hijau untuk \\
& menghidupkan UFM. \\
g. Nyalakan pompa LPG dan buka valve. \\
Selama Operasi \\
a. Posisikan tabung di dekat UFM. \\
b. Hubungkan nozzle yang terdapat pada UFM \\
$\quad$ dengan valve tabung.
\end{tabular}


INOBIS: Jurnal Inovasi Bisnis dan Manajemen Indonesia

Volume 1, Nomor 2, Maret 2018

Ratna Mentari; Andian Ari Istiningrum

c. Pastikan angka yang tampil pada CUC monitor $0,00 \mathrm{~kg}$.

d. Tekan F1/F2/F3 di CUC untuk memulai pengisian.

e. Bila angka pada monitor berhenti di $8,00 \mathrm{~kg}$ maka lepas nozzle dari valve tabung.

f. Lakukan tes kebocoran sesuai prosedur yang berlaku.

g. Pasang security seal cap pada tabung.

h. Pasang plastic wrap sesuai nama agen.

3 Penghentian

a. Matikan peralatan UFM dengan benar.

b. Matikan supply listrik ke peralatan UFM.

c. Flushing udara pada kompresor.

d. Matikan mesin pompa LPG.

e. Matikan pompa kompresor.

Sumber : Hasan, 2014

Tabel 5. Check List SOP Pengisian

\begin{tabular}{clll}
\hline No & \multicolumn{1}{c}{ Kriteria } & Ya & Tidak \\
\hline 1 & Tabung memasuki mesin pengisian UFM & & \\
2 & $\begin{array}{l}\text { Memastikan koneksi filling head dan valve tabung } \\
\text { terhubung baik }\end{array}$ & \\
3 & $\begin{array}{l}\text { Tabung yang keluar dari UFM ditimbang pada } \\
\text { timbangan cross check. }\end{array}$ & \\
4 & $\begin{array}{l}\text { Pengetesan kebocoran pada leak test dengan media } \\
\text { air. }\end{array}$ & \\
5 & Pemasangan seal cap dan plastic wrap. & \\
\end{tabular}

Sumber : Hasan, 2014

Tabel 6. Check List SOP Penyelesaian Pengisian

\begin{tabular}{clll}
\hline No & \multicolumn{1}{c}{ Kriteria } & Ya & Tidak \\
\hline 1 & Menyusun tabung isi ke truk dengan baik dan rapi. & & \\
2 & Menghitung tabung isi sesuai dengan jumlah yang & & \\
& tertera di loading order. & \\
3 & Mematikan UFM, transfer pump, dan sumber listrik & \\
& ketika proses pengisian selesai. & \\
4 & Menutup valve saluran LPG pada UFM. & \\
5 & Mematikan air compressor sesuai prosedur. & \\
\hline
\end{tabular}

Sumber : Hasan, 2014

Data yang dibutuhkan untuk memprediksi penjualan/penyaluran LPG kemasan tabung $3 \mathrm{~kg}$ berupa data sekunder yaitu penjualan LPG kemasan tabung $3 \mathrm{~kg}$ oleh Depot LPG X selama kurun waktu 2012-2016. Data tersebut dikumpulkan dengan teknik dokumentasi data penjualan pada bagian Sales \& General Administration di Depot LPG X. Prediksi penjualan/penyaluran LPG kemasan tabung $3 \mathrm{~kg}$ diperlukan sebagai dasar untuk merencanakan kebutuhan UFM selama periode waktu 5 tahun ke depan. 
INOBIS: Jurnal Inovasi Bisnis dan Manajemen Indonesia

Volume 1, Nomor 2, Maret 2018

Ratna Mentari; Andian Ari Istiningrum

Data untuk mengevaluasi kebutuhan UFM kemasan tabung $3 \mathrm{~kg}$ berupa data primer terdiri atas data kecepatan pengisian mesin UFM, waktu operasional, jumlah UFM untuk pengisian LPG kemasan tabung $3 \mathrm{~kg}$ diperoleh melalui observasi kinerja UFM di Depot LPG $\mathrm{X}$.

\section{Teknik Analisis Data}

Data efektivitas prosedur pengisian LPG kemasan tabung $3 \mathrm{~kg}$ dianalisis secara deskriptif dengan menggunakan tingkat efektivitas prosedur pengisian LPG kemasan tabung 3 $\mathrm{kg}$ yang dinyatakan dalam bentuk persentase. Formula yang digunakan untuk mengukur tingkat efektivitas prosedur pengisian LPG kemasan tabung $3 \mathrm{~kg}$ adalah sebagai berikut:

Tingkat Efektivitas $=\frac{\text { Jumlah Kriteria Dilakukan }}{\text { Jumlah Semua Kriteria }} \times 100 \%$

Prediksi penjualan/penyaluran LPG kemasan tabung $3 \mathrm{~kg}$ dilakukan dengan metode forecasting time series pattern. Terdapat dua jenis trend yang digunakan pada time series pattern, yaitu trend linier dan trend eksponensial. Model persamaan forecasting dengan trend liniear adalah sebagai berikut:

$Y^{\prime}=a+b X$

Dimana Y' merupakan nilai trend periode tertentu, a adalah konstanta atau nilai trend pada periode dasar, $\mathrm{b}$ adalah koefisien arah garis trend yang menggambarkan perubahan trend setiap periode, dan $\mathrm{X}$ adalah unit periode yang dihitung dari periode dasar (Makridakis, 1988).

Model persamaan forecasting dengan trend eksponensial adalah sebagai berikut:

$Y^{\prime}=a b^{X}$

Dimana $Y^{\prime}$ merupakan nilai trend periode tertentu, dan $\mathrm{X}$ adalah unit periode yang dihitung dari periode dasar (Makridakis, 1988)

Untuk memilih apakah trend linier atau trend eksponensial yang digunakan sebagai dasar melakukan peramalan penjualan/penyaluran LPG kemasan tabung $3 \mathrm{~kg}$ maka Average Absolut Error (AAE) untuk setiap jenis trend harus dihitung. Trend dengan AAE terkecil adalah trend yang digunakan dalam melakukan peramalan. Formula untuk menghitung AAE adalah sebagai berikut:

$\mathrm{AAE}=\frac{\sum\left|\mathrm{Y}-\mathrm{Y}^{\prime}\right|}{\mathrm{n}}$

Hasil dari peramalan penjualan/penyaluran LPG kemasan tabung $3 \mathrm{~kg}$ periode 20172021 digunakan sebagai dasar dalam mengevaluasi kebutuhan UFM pengisian tabung LPG kemasan tabung $3 \mathrm{~kg}$ selama periode 2017-2021. Evaluasi kebutuhan UFM dilakukan dengan menghitung kapasitas pemakaian UFM dengan formula sebagai berikut:

Kapasitas Pemakaian UFM $=\frac{\text { rata }- \text { rata pengisian per hari }}{\text { rata }- \text { rata kapasitas maksimal pengisian per hari }}$ 
INOBIS: Jurnal Inovasi Bisnis dan Manajemen Indonesia

Volume 1, Nomor 2, Maret 2018

Ratna Mentari; Andian Ari Istiningrum

Excess capacity terjadi ketika kapasitas pemakaian UFM melebihi $80 \%$ sehingga perlu dipertimbangkan penambahan UFM. Kriteria $80 \%$ digunakan sebagai batas normal capacity karena 20\% dari 100\% pemakaian UFM digunakan untuk keperluan pemeliharaan rutin UFM.

\section{Hasil dan Pembahasan}

\section{Efektivitas Prosedur Pengisian LPG Kemasan Tabung 3 Kg}

Prosedur pengisian LPG kemasan tabung $3 \mathrm{~kg}$ terdiri atas kelengkapan dokumen dan sarfas, administrasi pengisian, persiapan pengisian, pengisian, pengoperasian UFM, dan penyelesaian pengisian. Efektivitas prosedur pengisian LPG kemasan tabung $3 \mathrm{~kg}$ perlu dievaluasi untuk mengetahui kriteria-kriteria dalam SOP yang telah dilaksanakan maupun yang belum dilaksanakan. Jika ada kriteria dalam SOP yang belum dilaksanakan, maka perlu dianalisis penyebabnya, akibat jika kriteria tersebut tidak dilaksanakan, dan rekomendasi perbaikan. Tabel 7 memberikan hasil tingkat efektivitas prosedur pengisian LPG kemasan tabung $3 \mathrm{~kg}$.

Tabel 7. Tingkat Efektivitas Prosedur Pengisian LPG Kemasan Tabung 3 Kg

\begin{tabular}{clccc}
\hline No & \multicolumn{1}{c}{ Prosedur } & $\begin{array}{c}\text { Ya } \\
\text { (butir) }\end{array}$ & $\begin{array}{c}\text { Tidak } \\
\text { (butir) }\end{array}$ & $\begin{array}{c}\text { Tingkat } \\
\text { Efektivitas }\end{array}$ \\
\hline 1 & Kelengkapan dokumen dan sarfas & 13 & 0 & $100 \%$ \\
2 & Administrasi pengisian & 5 & 0 & $100 \%$ \\
3 & Persiapan pengisian & 6 & 0 & $100 \%$ \\
4 & Pengisian & 4 & 1 & $80 \%$ \\
5 & Pengoperasian UFM & 18 & 2 & $90 \%$ \\
6 & Penyelesaian pengisian & 5 & 0 & $100 \%$ \\
& Rata-rata Tingkat Efektivitas & & & $94,44 \%$ \\
\hline
\end{tabular}

Sumber : Data Primer Diolah, 2017

Tabel 7 menunjukkan bahwa rata-rata tingkat efektivitas prosedur pengisian LPG kemasan tabung $3 \mathrm{~kg}$ yaitu 94,44\%. Akan tetapi, masih terdapat kelemahan dalam melaksanakan proses pengisian dan pengoperasian UFM dimana ada 3 langkah dalam SOP yang tidak dilaksanakan sehingga analisis dan koreksi terhadap pelaksanaan kedua prosedur tersebut perlu dilakukan.

Pada proses pengisian, tabung yang keluar dari UFM tidak ditimbang pada timbangan cross check. Operator pengisian hanya memperhatikan berat tabung pada layar UFM tanpa melakukan cross check karena Depot LPG X tidak memiliki sarana dan fasilitas untuk melakukan cross check weighing. Meskipun demikian, keakuratan berat tabung tetap reliabel karena weighing system pada UFM sudah cukup akurat. Jika berat tabung pada layar UFM memiliki selisih $\pm 0,5 \mathrm{~kg}$ dari berat normal, maka UFM secara otomatis tidak akan melakukan pengisian LPG.

Pada proses pengoperasian UFM, prosedur yang tidak dilakukan yaitu prosedur pada saat persiapan pengoperasian UFM. Filling head pada UFM tidak diberi minyak, demikian juga dengan sisa angin pada kompresor tidak dibuang. Pekerja beranggapan bahwa kedua prosedur tersebut tidak harus rutin dilaksanakan setiap kali UFM hendak dioperasikan. Karena kedua prosedur tersebut tidak rutin dilakukan, UFM riskan mengalami kerusakan. Oleh karena itu, supervisor receiving, storage, and distribution hendaknya menegaskan 
INOBIS: Jurnal Inovasi Bisnis dan Manajemen Indonesia

Volume 1, Nomor 2, Maret 2018

Ratna Mentari; Andian Ari Istiningrum

kepada pekerjanya untuk secara rutin memberi minyak secukupnya pada filling head dan membuang sisa angin pada kompresor setiap kali UFM akan dioperasikan.

\section{Prediksi Penjualan/Penyaluran LPG Kemasan Tabung 3 Kg}

Prediksi penjualan/penyaluran LPG kemasan tabung $3 \mathrm{~kg}$ pada Depot LPG X untuk periode 2017-2021 perlu dilakukan untuk membuat perencanaan jumlah UFM yang dibutuhkan pada proses pengisian LPG kemasan tabung $3 \mathrm{~kg}$. Tabel 8 menunjukkan hasil model persamaan yang dapat dibentuk dari forecasting trend linier dan trend eksponensial.

Tabel 8. Model Persamaan Forecasting Trend Linier dan Eksponensial

\begin{tabular}{llllc}
\hline Trend & Nilai a & \multicolumn{1}{c}{ Nilai b } & \multicolumn{1}{c}{ Model Persamaan } & AAE \\
\hline Linier & $15.943,30$ & $1.388,65$ & $\mathrm{Y}^{\prime}=15.943,30+1.388,65 \mathrm{X}$ & 288,994 \\
Eksponensial & $15.816,80$ & 1,09 & $\mathrm{Y}^{\prime}=15.816,80 \times 1,09^{\mathrm{X}}$ & 322,057 \\
\hline
\end{tabular}

Sumber : Data Primer Diolah, 2017

Karena nilai AAE trend linier lebih kecil dari trend eksponensial, model persamaan yang digunakan untuk memprediksi penjualan/penyaluran LPG kemasan tabung $3 \mathrm{~kg}$ yaitu model persamaan forecasting dengan trend linier. Hasil prediksi disajikan pada Tabel 9.

Tabel 9. Prediksi Penjualan/Penyaluran LPG Kemasan Tabung 3 Kg

\begin{tabular}{lc}
\hline Tahun & Penjualan/Penyaluran (MT) \\
\hline 2017 & $20.109,25$ \\
\hline 2018 & $21.497,90$ \\
\hline 2019 & $22.886,56$ \\
\hline 2020 & $24.275,21$ \\
\hline$\sum$ & $25.663,86$ \\
\hline
\end{tabular}

Sumber : Data Primer Diolah, 2017

Permintaan LPG kemasan tabung $3 \mathrm{~kg}$ untuk wilayah kerja Depot LPG X dipenuhi oleh 4 SPBE. Mulai bulan Februari 2017, telah beroperasi SPBE baru yang juga melayani pengisian LPG sehingga terjadi penurunan kuota penyaluran di filling plant Depot LPG X sebesar 20\%. Oleh karena itu, prediksi penjualan/penyaluran LPG kemasan tabung $3 \mathrm{~kg}$ sebagaimana ditunjukkan pada Tabel 9 perlu disesuaikan dengan prediksi penurunan $20 \%$. Tabel 10 menunjukkan penyesuaian prediksi penjualan/penyaluran LPG Kemasan Tabung 3 Kg. Penjualan selama periode 2017-2021 diprediksi mengalami kenaikan sebesar 8,71\% per tahun yang dihitung dengan menggunakan laju pertumbuhan trend linier data ganjil.

Tabel 10. Penyesuaian Prediksi Penjualan/Penyaluran LPG Kemasan Tabung 3 Kg

\begin{tabular}{lc}
\hline Tahun & Penyesuaian Penjualan/Penyaluran (MT) \\
\hline 2017 & $16.087,40$ \\
\hline 2018 & $17.198,32$ \\
\hline 2019 & $18.309,24$ \\
\hline 2020 & $19.420,17$ \\
\hline$\sum$ & $20.531,09$ \\
\hline
\end{tabular}

Sumber : Data Primer Diolah, 2017 
INOBIS: Jurnal Inovasi Bisnis dan Manajemen Indonesia

Volume 1, Nomor 2, Maret 2018

Ratna Mentari; Andian Ari Istiningrum

\section{Evaluasi Kebutuhan UFM Pengisian LPG Kemasan Tabung 3 Kg}

Analisis terhadap kemampuan/kapasitas pemakaian mesin pengisian UFM perlu dilakukan terlebih dahulu sebelum mengevaluasi berapa jumlah UFM yang dibutuhkan pada tahun 2017-2021 untuk mengantisipasi kenaikan permintaan sebagaimana ditunjukkan dalam Tabel 10. Beberapa faktor perlu dipertimbangkan dalam melakukan analisis kapasitas pemakaian UFM, yaitu waktu pengisian dan waktu operasional depot.

Observasi pada salah satu truk yang memuat tabung sebanyak 560 tabung LPG $3 \mathrm{~kg}$ dilakukan untuk menghitung waktu bongkar muat LPG kemasan tabung $3 \mathrm{~kg}$. Hasil observasi ditunjukkan pada Tabel 11. Waktu untuk kegiatan filling, handling, dan loading sebagaimana ditunjukkan dalam Tabel 11 yaitu 18 menit untuk 560 tabung yang ditangani oleh 24 UFM. Dengan demikian, 1 UFM mengisi 23 tabung dengan total waktu 18 menit, sehingga 1 UFM mengisi 2 tabung selama 1 menit.

Tabel 11. Waktu Bongkar - Muat LPG Kemasan Tabung 3 Kg

\begin{tabular}{ll}
\hline \multicolumn{1}{c}{ Jam } & \multicolumn{1}{c}{ Kegiatan } \\
\hline 10.05 & Truk parkir dan siap bongkar \\
$10.08-10.09$ & Penghitungan jumlah tabung kosong \\
$10.09-10.30$ & Bongkar \\
$10.30-10.48$ & Filling + handling + loading \\
\hline
\end{tabular}

Sumber : Data Primer, 2017

Depot LPG X melaksanakan operasi pengisian pada hari kerja yaitu Senin - Jumat, sedangkan hari Sabtu dan Minggu serta hari libur nasional tidak dilakukan operasi pengisian. Dengan asumsi 1 tahun terdiri atas 365 hari, serta total hari Sabtu - Minggu dan libur nasional dalam 1 tahun yaitu 111 hari, maka jumlah hari operasional dalam setahun yaitu 254 hari.

Hasil perhitungan kapasitas UFM dengan asumsi kondisi sarfas lain dan manpower normal disajikan pada Tabel 12. Kapasitas pemakaian UFM pada tahun 2016 sebagaimana disajikan pada Tabel 12 yaitu 120,25\%. Hal ini menunjukkan terjadinya excess capacity karena kapasitas pemakaian lebih dari $80 \%$. Hasil perhitungan diperkuat dengan observasi di lapangan yang menunjukkan bahwa antrean panjang terjadi dalam proses pengisian LPG kemasan tabung $3 \mathrm{~kg}$.

Tabel 12. Proses Perhitungan Kapasitas Pemakaian UFM Tahun 2016

\begin{tabular}{ll}
\hline \multicolumn{1}{c}{ Keterangan } & \multicolumn{1}{c}{ Perhitungan } \\
\hline Kecepatan pengisian UFM & 2 tabung/menit \\
Waktu operasional per hari & 7 jam operasional = 420 menit \\
Jumlah UFM LPG kemasan tabung $3 \mathrm{~kg}$ & 24 unit \\
Total LPG kemasan tabung $3 \mathrm{~kg}$ yang & $=$ kecepatan pengisian UFM x \\
mampu diisi dalam 1 hari & $\quad$ waktu operasional per hari x \\
& jumlah UFM \\
$=$ & $2 \times 420 \mathrm{x} 24$ \\
& $=20.160$ tabung \\
& $=20.160$ tabung x $3 \mathrm{~kg}$ \\
Total volume maksimal LPG yang & $=60.480 \mathrm{~kg}$ \\
dijual/disalurkan dalam 1 hari & $=60,48 \mathrm{MT}$ \\
& $=$ penjualan aktual 2016/254 hari \\
Total volume aktual LPG yang & $=18.473,64 / 254$ \\
dijual/disalurkan dalam 1 hari pada tahun & $=72,73 \mathrm{MT}$ \\
2016 &
\end{tabular}


INOBIS: Jurnal Inovasi Bisnis dan Manajemen Indonesia

Volume 1, Nomor 2, Maret 2018

\section{Ratna Mentari; Andian Ari Istiningrum}

Kapasitas Pemakaian UFM pada tahun 2016

$$
\begin{aligned}
= & \text { volume aktual / volume } \\
& \text { maksimal } \\
= & 72,72 \mathrm{MT} / 60,48 \mathrm{MT} \\
= & 1,2025 \\
= & 120,25 \%
\end{aligned}
$$

Sumber : Data Primer Diolah, 2017

Dengan cara yang sama seperti pada Tabel 12, maka prediksi kapasitas pemakaian tahun 2017 sampai dengan 2021 dapat dilakukan sebagaimana ditunjukkan pada Tabel 13.

Tabel 13. Kapasitas Pemakaian UFM Tahun 2017 - 2021

\begin{tabular}{lcccc}
\hline Tahun & $\begin{array}{c}\text { Prediksi } \\
\text { Penjualan/ } \\
\text { Penyaluran per } \\
\text { Tahun (MT) }\end{array}$ & $\begin{array}{c}\text { Prediksi } \\
\text { Penjualan/ } \\
\text { Penyaluran per } \\
\text { Hari (MT) }\end{array}$ & $\begin{array}{c}\text { Volume } \\
\text { Maksimal } \\
\text { per Hari } \\
(\text { MT) }\end{array}$ & $\begin{array}{c}\text { Kapasitas } \\
\text { Pemakaian } \\
(\%)\end{array}$ \\
\hline 2017 & $16.087,40$ & 63,33 & 60,48 & 104,72 \\
2018 & $17.198,32$ & 67,71 & 60,48 & 111,95 \\
2019 & $18.309,24$ & 72,08 & 60,48 & 119,19 \\
2020 & $19.420,17$ & 76,46 & 60,48 & 126,42 \\
2021 & $20.531,09$ & 80,83 & 60,48 & 133,65 \\
\hline
\end{tabular}

\section{Sumber : Data Primer Diolah, 2017}

Prediksi kapasitas pemakaian UFM pengisian LPG kemasan tabung $3 \mathrm{~kg}$ pada tahun 2017 sampai dengan tahun 2021 melebihi kapasitas normal 80\% sehingga perlu dilakukan penambahan jumlah UFM. Tabel 14 dan 15 menunjukkan beberapa alternatif perkiraan UFM yang perlu ditambahkan. Cara menghitung kapasitas pemakaian dengan tambahan UFM analog dengan perhitungan pada Tabel 12.

Tabel 14. Alternatif Penambahan UFM Tahun 2017

\begin{tabular}{cccc}
\hline $\begin{array}{c}\text { Tambahan } \\
\text { UFM } \\
\text { (Unit) }\end{array}$ & $\begin{array}{c}\text { Prediksi Penjualan/ } \\
\text { Penyaluran per Hari } \\
(\mathrm{MT})\end{array}$ & $\begin{array}{c}\text { Volume } \\
\text { Maksimal per } \\
\text { Hari (MT) }\end{array}$ & $\begin{array}{c}\text { Kapasitas Pemakaian } \\
(\%)\end{array}$ \\
\hline 1 & 63,33 & 63 & 100,53 \\
\hline 2 & 63,33 & 65,52 & 96,67 \\
\hline 3 & 63,33 & 68,04 & 93,09 \\
\hline 4 & 63,33 & 70,56 & 89,76 \\
\hline 6 & 63,33 & 75,60 & 83,37 \\
\hline 7 & 63,33 & 78,12 & 81,08 \\
\hline 8 & 63,33 & 80,64 & 78,54 \\
\hline
\end{tabular}

Sumber : Data Primer Diolah, 2017

Tabel 15. Alternatif Penambahan UFM Tahun 2021

\begin{tabular}{cccc}
\hline $\begin{array}{c}\text { Tambahan } \\
\text { UFM }\end{array}$ & $\begin{array}{c}\text { Prediksi Penjualan/ } \\
\text { Penyaluran per Hari }\end{array}$ & $\begin{array}{c}\text { Volume } \\
\text { Maksimal per } \\
\text { (Unit) }\end{array}$ & $\begin{array}{c}\text { Kapasitas Pemakaian } \\
(\%)\end{array}$ \\
\hline 1 & 80,83 & 63 & 128,37 \\
2 & 80,83 & 65,52 & 123,37
\end{tabular}


INOBIS: Jurnal Inovasi Bisnis dan Manajemen Indonesia

Volume 1, Nomor 2, Maret 2018

Ratna Mentari; Andian Ari Istiningrum

\begin{tabular}{rccc}
13 & 80,83 & 93,24 & 86,69 \\
15 & 80,83 & 98,28 & 82,24 \\
16 & 80,83 & 100,80 & 80.18 \\
\hline
\end{tabular}

Sumber : Data Primer Diolah, 2017

Berdasarkan pada hasil perhitungan Tabel 14 dan 15 maka pada tahun 2017 perlu dilakukan penambahan 7 UFM. Penambahan dilakukan secara bertahap hingga memenuhi tambahan 16 UFM pada tahun 2021. Tambahan UFM bisa dilakukan dengan menggunakan UFM pengisian tabung $12 \mathrm{~kg}$. Berdasarkan hasil observasi di lapangan, UFM pengisian tabung $12 \mathrm{~kg}$ memiliki idle capacity yang cukup besar, sehingga akan lebih baik jika UFM tersebut digunakan untuk membantu pengisian tabung $3 \mathrm{~kg}$ yang sudah mengalami overload.

\section{Penutup}

Hasil penelitian menunjukkan bahwa prosedur pengisian LPG kemasan tabung $3 \mathrm{~kg}$ di Depot LPG X sudah berjalan dengan efektif dengan tingkat efektivitas sebesar 94,44\%. Kapasitas pemakaian UFM dari tahun 2017-2021 melebihi normal capacity sehingga perlu dilakukan penambahan UFM sebanyak 7 unit pada tahun 2017 hingga 16 unit pada tahun 2021. Penambahan tersebut perlu dilakukan untuk memenuhi target penjualan/penyaluran LPG kemasan tabung $3 \mathrm{~kg}$ yang laju pertumbuhannya meningkat sebesar 8,71\% selama periode 2017-2021. Keterbatasan penelitian ini yaitu observasi untuk mengevaluasi efektivitas pelaksanaan SOP pengisian LPG tabung kemasan $3 \mathrm{~kg}$ hanya terbatas pada apakah SOP tersebut dilaksanakan di lapangan atau tidak. Observasi tidak didasarkan pada apakah semua SOP sudah dilaksanakan dengan tepat dan akurat. Oleh karena, penelitian selanjutnya diharapkan mampu mengeliminasi keterbatasan tersebut dengan melakukan observasi SOP pengisian LPG dengan lebih mendetail. Keterbatasan lain dalam penelitian ini yaitu studi kelayakan penambahan UFM hanya dilakukan dari sisi pemasaran dan teknis saja, sehingga penelitian selanjutnya diharapkan dapat menambah studi kelayakan dari sisi ekonomis.

\section{Daftar Pustaka}

Gumelar, G. 2015. 2016, Konsumsi LPG 3 Kg Diperkirakan Naik 14,5 Persen. https://www.cnnindonesia.com/ekonomi/20150622154146-85-61619/2016-

konsumsi-elpiji-3-kg-diperkirakan-naik-145-persen/ . Diakses tanggal 2 Mei 2017.

Hasan, M. S. 2014. Pedoman Tata Kerja Organisasi. Jakarta: PT Pertamina Persero.

Makridakis, S. S. 1988. Metode dan Aplikasi Peramalan. Jakarta: Erlangga.

The Kosan Crisplant Group. 2014. System Equipment and Services for the LPG Industry. Denmark: Kosan Crisplant.

PT Pertamina. 2007. Elpiji. http://www.pertamina.com/our-business/hilir/pemasaran-danniaga/produk-dan-layanan/solusi-bisnis/gas-produk/lpg/. Diakses tanggal $6 \mathrm{Mei}$ 2017.

Rizky. 2007. Konversi Minyak Tanah ke LPG 3 Kg. http://www.migas.esdm.go.id/post/read/konversi-minyak-tanah-ke-lpg-3-kg. Diakses tanggal 6 Mei 2017. 